\title{
Update on Presbyopia-correcting Drops
}

\author{
Feyza Çalis Karanfil and Burak Turgut \\ Yuksek Intisas University, Faculty of Medicine, Department of Ophthalmology, Ankara, Turkey
}

DOI: https://doi.org/10.17925/EOR.2017.11.02.99

\section{Keywords}

Presbyopia, para-sympathomimetic, accommodation, ciliary muscle contraction, drop treatment, myosis, lens softening, increased focus depth

Disclosure: Feyza Çalis Karanfil and Burak Turgut have nothing to declare in relation to this article.

Compliance with Ethics: This study involves a review of the literature and did not involve any studies with human or animal subjects performed by any of the authors.

Authorship: All named authors meet the Internationa Committee of Medical Journal Editors (ICMJE) criteria for authorship of this manuscript, take responsibility for the integrity of the work as a whole, and have given final approval to the version to be published.

open Access: This article is published under the Creative Commons Attribution Noncommercial License, which permits any non-commercial use, distribution, adaptation and reproduction provided the original author(s) and source are given appropriate credit.

Received: 24 October 2017

Accepted: 5 December 2017

Citation: European Ophthalmic Review, 2017;11(2):99-102

Corresponding Author: Burak Turgut, Yuksek

Intisas University, Faculty of Medicine, Department of Ophthalmology, 06520, Ankara, Turkey.

E: burakturgut@yiu.edu.tr

Support: No funding was received in the publication of this article.
Presbyopia is progressive age-related reduction in accommodation amplitude and the loss of ability of the eye to focus on near objects. It occurs in almost everyone at around 40 years of age. ${ }^{1-5}$ Presbyopia affects visual tasks at near distance such as book reading, handcrafts, stitching, cooking and surgical operation. Thus, it causes the diminishing of vision-targeted life quality and occupational performance of many people over $40 . .^{1-5}$

The physiopathology of presbyopia is not clearly known. However, it has been demonstrated that various factors including the hardening of the lens, changes in the elasticity of the lens capsule, lens dimension, geometry of zonular attachments and ciliary muscle contraction may be responsible for the accommodative loss in presbyopia. ${ }^{1,2}$

Accommodation in humans is performed by ciliary muscle (CM) and iris sphincter contractions, convergence and changes in the shape and position of the lens. The muscles of the iris and ciliary body are stimulated by the parasympathetic system. The parasympathetic cholinergic stimulation causes the contraction of the $\mathrm{CM}$ and myosis, providing the increase of focus depth and the shape and position of the lens both to change and for accommodation to develop. ${ }^{3}$

In an eye which is un-accommodated and looks at a distant object, CM is relaxed; the anterior zonular fibers (ZF) are stretched by traction from the posterior ZF. Then, anterior ZF flattens the lens. In the accommodated eye, the forward and inward movement of the ciliary muscle allows the tension fiber system to take up the tractional forces from the posterior ZF and releases the tension in the anterior ZF; both the thickness and refractive power of the lens increase. ${ }^{3-5}$

There are some surgical modalities including refractive lens exchange, mono-vision laser-assisted in situ keratomileusis (LASIK), blended vision LASIK, multifocal or accommodating intraocular lens (IOL) implantations and corneal inlay implantation for the treatment of presbyopia..$^{4-7}$ Nonsurgical treatments for presbyopia include the use of near-glasses and contact lenses. ${ }^{5}$ Nowadays, otorities are speculating about topical parasympathomimetic drop treatment for pharmacological control of presbyopia, which is a nonsurgical option for the vast majority of people with near vision spectacle dependence over 40 years old. ${ }^{8}$

Presbyopia treatment modalities are based on reducing pupil sizes because smaller pupil sizes increase near visual acuity by increasing focus depth. Also, central light waves reach the retina, which results in clearer vision. A drop for presbyopia treatment must create a similar and longlasting effect on pupil apertures to be successful.? The commercial and noncommercial drops used or tried in the treatment of presbyopia are given in Table 1. Reducing pupil size is not without adverse effects. A constricted pupil decreases vision at night - less light enters the eye, and diffraction at very small pupil sizes can decrease overall vision quality and also lead to myopic shift compromising distance vision. To reduce this side effect drops can be used monocularly. Even monocular pharmacological treatment with a single miotic agent has been shown to result in acceptable reading vision for many presbyopes, even older recipients. But a 
Table 1: The commercial and noncommercial drops used or tried in the treatment of presbyopia

\begin{tabular}{|c|c|c|}
\hline $\begin{array}{l}\text { Preparation } \\
\text { name }\end{array}$ & Content & Action \\
\hline No name ${ }^{8}$ & $\begin{array}{l}\text { - } \quad \text { Pilocarpine } 1 \% \\
\text { - } \text { Diclofenac } 0.1 \%\end{array}$ & $\begin{array}{l}\text { - } \text { Miosis } \\
\text { - } \text { CM contraction } \\
\text { - } \text { Reduce inflammation }\end{array}$ \\
\hline No name $e^{8,9}$ & $\begin{array}{l}\text { - } \quad \text { Pilocarpine } 1 \% \\
\text { - } \text { Dexamethasone }\end{array}$ & $\begin{array}{ll}\text { - } & \text { Miosis } \\
\text { - } & \text { CM contraction } \\
\text { - } & \text { Reduce inflammation }\end{array}$ \\
\hline No name ${ }^{12}$ & $\begin{array}{l}\text { - } \text { Pilocarpine } 1 \% \\
\text { - } \text { Brimonidine } 0.2 \%\end{array}$ & $\begin{array}{l}\text { - } \text { Miosis } \\
\text { - } \mathrm{CM} \text { contraction }\end{array}$ \\
\hline No name ${ }^{13}$ & $\begin{array}{l}\text { - } \text { Pilocarpine } 1 \% \\
\text { - } \quad \text { Brimonidine } 0.2 \%\end{array}$ & $\begin{array}{l}\text { - } \text { Miosis } \\
\text { - } \quad \text { CM contraction }\end{array}$ \\
\hline $\begin{array}{l}\text { Vejarano } \\
\text { drop }^{15}\end{array}$ & $\begin{array}{ll}\text { - } & \text { Pilocarpine } 0.247 \% \\
\text { - } & \text { Phenylephrine } 0.78 \% \\
\text { - } & \text { Polyethyleneglycol } 0.09 \% \\
\text { - } & \text { Nepafenac } 0.023 \% \\
\text { - } & \text { Pheniramine } 0.034 \% \\
\text { - } & \text { Naphazoline } 0.003 \%\end{array}$ & $\begin{array}{l}\text { - } \text { Miosis } \\
\text { - } \text { mydriasis contraction, } \\
\text { - } \text { CM relaxation } \\
\text { - } \text { Lubrication } \\
\text { - } \text { Reduce } \\
\text { inflammation and } \\
\text { parasympathomimetics } \\
\text { adverse effects }\end{array}$ \\
\hline PresbiDrops $^{18}$ & $\begin{array}{l}\text { Unknown exact active } \\
\text { ingredients; authors } \\
\text { state combination of } \\
\text { parasympathomimetic and } \\
\text { NSAID }\end{array}$ & $\begin{array}{l}\text { - } \text { Miosis } \\
\text { - } \text { Reduce inflammation }\end{array}$ \\
\hline No name ${ }^{21}$ & $\begin{array}{l}\text { - } \quad \text { Pilocarpine } 1 \% \\
\text { - } \quad \text { Bromfenac } 0.0018 \%\end{array}$ & $\begin{array}{ll}\text { - } & \text { Miosis } \\
\text { - } & \text { CM contraction } \\
\text { - } & \text { Reduce inflammation }\end{array}$ \\
\hline PresbyPlus ${ }^{22}$ & $\begin{array}{l}\text { - Two } \\
\text { parasympathomimetics } \\
\text { - One parasympatholytic }\end{array}$ & $\begin{array}{l}\text { - } \text { Miosis } \\
\text { - } \text { CM contraction } \\
\text { parasympathomimetics } \\
\text { adverse effects }\end{array}$ \\
\hline $\begin{array}{l}\text { Presbyeye } \\
\text { drops }^{9}\end{array}$ & $\begin{array}{l}\text { Unknown exact active } \\
\text { ingredients; authors } \\
\text { state combination of } \\
\text { parasympathomimetic } \\
\text { and NSAID }\end{array}$ & $\begin{array}{l}\text { - } \text { Miosis } \\
\text { - Reduce inflammation }\end{array}$ \\
\hline PresbV drops ${ }^{39}$ & $\begin{array}{l}\text { Pilocarpine (unknown } \\
\text { strengths) } \\
\text { - Phenylephrine (unknown } \\
\text { strengths) }\end{array}$ & $\begin{array}{l}\text { - } \text { Miosis } \\
\text { - } \text { CM contraction } \\
\text { - } \text { Mydriasis } \\
\text { - } \text { Vasocon relaxation } \\
\text { - }\end{array}$ \\
\hline PRX-100 23,24 & $\begin{array}{l}\text { - Aceclidine } \\
\text { - Tropicamide }\end{array}$ & $\begin{array}{l}\text { Miosis without } \\
\text { stimulating } \\
\text { accommodation }\end{array}$ \\
\hline $\begin{array}{l}\text { AGN-190584 } \\
\text { and AGN- } \\
199201^{32-34}\end{array}$ & $\begin{array}{l}\text { - Presumed to be } \\
\text { oxymetazoline and the } \\
\text { unknown agent }\end{array}$ & $\begin{array}{l}\text { - } \text { Miosis } \\
\text { - } \text { Mydriasis } \\
\text { effects }\end{array}$ \\
\hline EVO6 $^{25-29}$ & $\begin{array}{l}\text { Choline ester of the lipoid } \\
\text { acid }\end{array}$ & - Lens softening \\
\hline Liquid vision $^{19}$ & $\begin{array}{l}\text { - Aceclidine } \\
\text { - Tropicamide (a cycloplegic) }\end{array}$ & $\begin{array}{l}\text { - } \text { Miosis } \\
\text { - } \text { CM contraction } \\
\text { for moderating } \\
\text { accommodation }\end{array}$ \\
\hline
\end{tabular}

$C M=$ Ciliary muscle; $N S A I D=$ nonsteroidal anti-inflammatory drugs. mono-vision treatment could degrade visual performance in reduced light conditions compared to a binocular approach. In monocular treatment, the vision in the fellow eye with the normal pupil will have some blurry near vision, but distant objects are clear and there is no diminished light perception. When the images are merged, patients may have clear focus at near and distance with no perception of dimness. The reduction of the amount of light falling on the retina may cause the worsening of the vision, especially in elderly patients. ${ }^{5,8}$ However, the increasing of the illumination may decrease these complaints.

Muscarinic agonistic agents cause miosis, increase the depth of focus and create pseudo-accommodation. However, parasympathomimetic drops with muscarinic stimulation of anterior uveal tract such as carbachol, pilocarpine and physostigmine, an anti-cholinesterase inhibitor, cause chronic inflammation and stimulation of fixed pupil, posterior synechiae and spasmodic contractions of the iris and $\mathrm{CM}$, pigment dispersion, eventually a fixed pupil and myopic shift. Thus, some additional drops including non-steroidal anti-inflammatory drugs (NSAIDS) or steroids should be combined with pilocarpine for the elimination of local inflammation. ${ }^{8,9}$ The use of a combination of pilocarpine $1 \%$ and diclofenac $0.1 \%$ four times restores near vision without causing blurred far- and half-distance vision or inflammatory reactions. ${ }^{8.9}$ It has been reported that a combination of dexamethasone and pilocarpine prevents an inflammatory reaction, restores near vision but not far- and half-distance vision. ${ }^{8}$ The NSAIDs block cyclooxygenase, and decrease the hyper-parasympathomimetic effects of anticholinesterase inhibitors; they inhibit the inflammation in the anterior uveal tract, decrease spasmodic ciliary contraction, pigment dispersion and posterior synechia formation secondary to parasympathomimetic drugs and also they prolong the parasympathomimetic agent's effect by prostaglandin synthesis inhibition in the anterior uvea. ${ }^{8-10}$

Muscarinic agonist with sympathetic agonist is another option for presbyopia treatment. Carbachol is a parasympathomimetic agent and, unlike pilocarpine, is a full agonist that also supports acetylcholine release from parasympathetic nerve endings. Additionally, it may also inhibit cholinesterase enzymes by its carbamate structure. ${ }^{10}$ In terms of inducing miosis, the most commonly used strength of carbachol is $2.25 \%$ (which is equivalent in effect to about $3 \%$ pilocarpine). ${ }^{11}$ Brimonidine is a a2-receptor agonist, used in glaucoma, exhibits pupillary action, and can make significant miosis, typically in low light conditions. ${ }^{12}$

A study evaluating the efficacy of a combination of carbachol $2.25 \%$ and brimonidine $0.2 \%$ eye drops monocular once daily for 3 months demonstrated that the combination provided a significant improvement in near visual acuity without any change in distance vision through improving the depth of focus and making the miosis. ${ }^{13}$ The same study group has recently published the results of another clinical trial, which compares the $3 \%$ carbachol with brimonidine $0.2 \%$ in only 10 patients and they showed statistically significant results again..$^{15}$ Given that they recruited almost five times as many patients for the $2.25 \%$ formulation, one can infer the formulation they likely favour. ${ }^{13}$

In a recent study, it was reported that another combination designed by $\mathrm{Dr}$ Vejarano including pilocarpine $0.247 \%$, phenylephrine $0.78 \%$, polyethylene glycol $0.09 \%$, nepafenac $0.023 \%$, pheniramine $0.034 \%$ and naphazoline $0.003 \%$ maintained the stimulation of the contraction of the $\mathrm{CM}$ and the physiological pupil diameter variation. Vejerano has suggested that this drop prevented the worsening of visual performance in the dark and provided physiological images merging with clear focus at all distances. ${ }^{15}$ Pilocarpine shows its positive 
effect on accommodation by providing both miosis and ciliary body contraction. ${ }^{8,9,15}$ Phenylephrine, nepafenac and pheniramine prevent excess miosis and counteract ciliary muscle spasm, vascular congestion and hyperemia induced by pilocarpine. ${ }^{15}$ Naphazoline empowers the relaxing effect of pilocarpine on dilator pupillary muscle and relieves its side effects by increasing acetylcholine release and reducing norepinephrine release. ${ }^{15}$

The lubricating effect of polyethylene glycol makes the drops more tolerable by preventing the burning effect of the compounds and improves the tolerance for using these drops. ${ }^{16}$ The synergistic effect observed by vejerano between these compounds permits improved near vision and preserves distance vision in all subjects. The results showed a mean uncorrected near visual acuity (UNVA) improvement by about 2 to 3 lines in each eye. No patient had a loss of uncorrected distance visual acuity (UDVA) in each eye and binocularly. The synergism reduces symptoms of headache hyperemia and allows lower doses of the miotics to be used. ${ }^{17}$ In this study, Vejarano reported that the pupil diameter appeared significantly increased in photopic conditions only for the first hour and it appeared significantly decreased in scotopic condition between 4 and 5 hours after instillation of the drop. Pupil diameter was found to be mildly affected by the topical treatment, which is not fixed, allowing a 'dynamic pseudoaccommodation' and measurements showed that the treatment seemed to reduce significant pupil enlargement under scotopic conditions, as well as significant contraction in photopic conditions. ${ }^{15,17}$

PresbiDrops includes a combination of a parasympathomimetic agent with a NSAID in an oil-based formulation. However, the exact active ingredients of the drop are unknown. It has provided significant improvements in both near and distant visual acuities. ${ }^{18}$

Liquid vision, binocularly instilled, has a pure miotic effect without stimulation of accommodation. The rationale is to produce a pinhole effect, avoiding the ciliary muscle contraction that would cause a myopic shift, worsening far vision. The company claims a rapid effect on the pupil that leads a stable pupil diameter of approximately $1.6 \mathrm{~mm}$, with a duration action of approximately 8 hours. In the preliminary trials performed by Dr Castillo, UNVA improved 3 to 7 lines on the Jaeger scale without compromising distance vision. ${ }^{19}$

Presbyeyedrops is another eye drop based on a combination of two parasympathomimetic agents (unknown exact active ingredients and a NSAID). It has been reported that drop treatment provided improvements in both UDVA and UNVA. ${ }^{9}$

Muscarinic agonist and alpha agonist or a COX-2 selective NSAID pharmacology of NSAIDS goes one step further. NSAIDs inhibit the cyclooxygenase (COX) enzyme family, which is responsible for prostaglandin and thromboxane synthesis. Humans have two functional coX isoforms, COX-1 and COX-2, coX-2 typically being expressed in the inflamed tissue. Abad's patent identifies using COX-2-specific inhibitors in combination with a cholinergic or muscarinic agent in an attempt to target COX-2-specific pro-inflammatory mediator production but sparing the prostanoid production related to $\mathrm{COX}-1 .{ }^{20}$

Rodríguez and Carrera combined pilocarpine with bromfenac, a NSAID. Their aim was to increase the duration of action due to bromfenac to 24 hours, and this allowed for a once-daily topical application - unlike diclofenac, which has an ocular half-life of fewer than 2 hours. However, to date no published studies are available on this formulation. ${ }^{21}$
Another eye drop that stimulates the ciliary muscle to accommodate and constrict the pupil is based on the proprietary components of PresbyPlus: two parasympathomimetic agents and one parasympatholytic. These eye drops were instilled bilaterally twice a day in a clinical trial that showed that $90 \%$ of subjects could see $\mathrm{J} 4$ to J1 within 1 year without adverse reactions. ${ }^{22}$

PRX-100 is a combination of muscarinic agonist and an antagonist, a registered preparation developed by 'Presbyopia Therapies', which contains aceclidine and tropicamide. Tropicamide, a mydriatic is an antimuscarinic agent; aceclidine is a muscarinic agonist which is less potent than pilocarpine and carbachol. This drop is an eye drop which causes miosis without the typical accommodative effect. This constriction increases the focus depth and it provides improvement in near vision without impairment in distance vision with the pinhole effect. The pinhole allows light to be focused more centrally on the retina, improving the clarity of vision across a range of distances. This smaller pupil size reduces the light that is received by the retina, improves the contrast sensitivity, and eliminates stray light. ${ }^{23}$ Tropicamide has the opposite effect of aceclidine. Tropicamide has a much higher affinity for iris M3 receptors (as opposed to ciliary $\mathrm{M} 3$ receptors) than other anti-muscarinic agents. This effect allows pupil dilation with minimal influence on accommodation. It may diminish the spasm of sphincter papillae with the minimal unwanted antagonism of ciliary contraction that is required for accommodation. PRX-100 drop shows its effect in 30 minutes following application and its effect continues about 5 hours. In a study, it has been reported that all of the participants with presbyopia experienced marked improvement in near vision with the unique side effect of short-term dimming in vision due to decreasing of the amount of light which entered into the eye with pupil constriction. ${ }^{23,24}$

Recently, it has been reported by Encore Vision/Novartis that EV06 ophthalmic solution including lipoic acid choline ester $1.5 \%$ improved binocular near acuity with no loss of the best-corrected distance vision. It is well known that the aging of crystalline lens diminishes the elasticity of the lens through the increasing protein sulfhydryl group oxidation to form protein cross-links, and the lens fibres harden and consequently, this causes accommodative amplitude loss and blurry near vision. ${ }^{25-29}$ EV06 is a prodrug penetrating the cornea which metabolizes to an organic compound to two natural substances: lipoic acid and choline. EVO6 is catabolised by cellular esterases, increases lens elasticity by decreasing the number of protein-disulfide bonds and makes the crystalline lens more elastic and softer via natural un-crosslinking. ${ }^{27-29}$

Liquid Vision drops provide a temporary presbyopia-correcting therapeutic effect designed to last five hours or longer. Its phase IIb trial is continued. Liquid Vision eye drop contains aceclidine (a miotic) and tropicamide (a cycloplegic) to provide a 'super pinhole' effect and moderate accommodation. Aceclidine is used for creating the pinhole effect but by itself, this creates strong accommodation, including ciliary spasm and distance vision blur. Tropicamide reduces accommodation. Mutual effect between these two drugs improves both near and distance vision simultaneously. This drop shows action within 30 minutes after using. It is using binocularly and is designed to make better near and distance vision. Presbyopia Therapies added tropicamide to a formulation for moderating accommodation and reducing the ciliary side effects. Patients who have lens opacities may complain about ocular scatter related to small aperture optics. This is the disadvantage of the brimonidine-carbachol drop. The big advantage is that if it does not work, patients can give up using the drop, as long as no long-term detrimental effects are discovered. ${ }^{23,24,30}$ 
FOV Tears, a binocular presbyopia-correcting drop is a combination of parasympathetic, alpha agonists 1 and 2, an anti-cholinesterase and a NSAID. The drop affects the ciliary muscle, which causes a physiological accommodation and a dynamic pseudo-accommodation. At the end of the third month of use, all participants did not need near eye-glasses for normal activities. ${ }^{31}$

In a recent study, a combination of carbachol 3\% and brimonidine $0.2 \%$ drop for presbyopia correction provided statistically significant improvement in mean near visual acuity in all subjects who used combined carbachol $3 \%$ and brimonidine $0.2 \%$ in the same formulation compared with those who used separate forms. Additionally, the monocular treatment with one drop a day of a combination of carbachol and brimonidine in the non-dominant eye permitted acceptable reading vision for the majority of older subjects with presbyopia. This drop constricts the pupil and increases the depth of focus with the pinhole effect, similar to the corneal inlay. ${ }^{13}$

AGN-199201 (estimated to be an $\alpha$-sympathomimetic agent oxymetazoline, and AGN-190584 (an unknown agent) are two compounds investigating by Allergan. ${ }^{32}$ Phase II clinical trials of AGN-199201 has been completed and some results have been published. ${ }^{33}$ AGN-190584 has been registered and patient recruitment has yet to begin. Oxymetazoline is an $\alpha$-adrenergic agonist, has a vasoconstrictive effect and is used as an ocular anti-hyperemia agent. At the same time, it produces mydriasis by the $\alpha$-receptor agonistic effect on the iris dilator muscles, which decreases the depth of focus and unwanted effects in presbyopia treatment. AGN-199201 may be added to the formulation to reduce the adverse effects of AGN-190584, like hyperemia or strengthen the effect of AGN-190584 by decreasing systemic absorption and elongating retention time in the eye. ${ }^{32-34}$
Another option for presbyopia treatment is using sympathetic antagonist with muscarinic agonist. A muscarinic agonist and an $\alpha$-sympathetic antagonist agent could act synergistically on miosis, increase pseudo-accommodation and also decrease ciliary body spasm. The decrease in pupil size increases focus depth and hence improves UNVA. There are two formulations: pilocarpine with dapiprazole and pilocarpine with thymoxamine. ${ }^{35}$ Thymoxamine is a competitive post-junctional $\alpha 1$-antagonist. Sympathetic innervation has very little effect on the ciliary muscle (as opposed to muscarinic agonistic effect), thymoxamine changes the pupil size without affecting the ciliary muscle significantly. The half-life of thymoxamine is ten times longer than the 1 hour half-life belonging pilocarpine. ${ }^{37}$ Ninety minutes later, after using thymoxamine pupil diameter reduces about $1.6 \mathrm{~mm}$ and accommodation increases 1 D. ${ }^{37}$

Dapiprazole is another sympathetic antagonist, which has a same mechanism of action as thymoxamine. In a study, dapiprazole $0.5 \%$ has been used, accommodation increased much more with two drops than one drop and brown eyes had a slower response. ${ }^{38}$

The other group of sympathetic agents is $\alpha$-blockers. There are $\alpha$-adrenergic receptors on the iris and also the ciliary muscle. The $\alpha$-blockers create CM contraction, myosis, and increase accommodation. Timolol has some important systemic side effects which limited its usage. Neufeld prepared and patented a drop which contains only $\alpha$-blockers, but no study has been done about its effect on presbyopia. ${ }^{39}$

In conclusion, pharmacological drop treatment may contribute to the development of a useful treatment modality for some presbyopic subjects with specific near-vision needs; although further studies are needed to clearly understand its advantages and limitations. $\square$
1. Croft MA, Kaufman PL, Accommodation and presbyopia: the ciliary neuromuscular view, Ophthalmol Clin North Am, the ciliary neurom

2. Charman WN, The eye in focus: accommodation and presbyopia, Clin Exp Optom, 2008;91:207-225.

3. Rohen JW, Scanning electron microscopic studies of the zonula apparatus in human and monkey eyes, Invest Ophthalmol Vis SCi, 1979; 18:133-44.

4. Glasser A, Restoration of accommodation: surgical options for correction of presbyopia, Clin Exp Optom, 2008;91:279-95.

5. Charman WN, Developments in the correction of presbyopia I: spectacle and contact lenses, Ophthalmic Physiol Opt, 2014;34:8-29.

6. Charman WN, Developments in the correction of presbyopia II: surgical approaches, Ophthalmic Physiol Opt, 2014;34:397-426.

7. Gil-Cazorla R, Shah S, Naroo SA, A review of the surgical options for the correction of presbyopia, Br J Ophthalmol, 2016:100:62-70.

8. Benozzi J, Benozzi G, Orman B, Presbyopia: a new potential pharmacological treatment, Med Hypothesis Discov Innov Ophthalmol, 2012;1:3-5

9. Patel S, Salamun F, Matovic K. Pharmacological correction of presbyopia. Poster presented at the XXXI Congress of the ESCRS. 5-9 October 2013. Amsterdam. Available at: http://escrs. org/amsterdam2013/programme/posters-details.asp?id=1980 (accessed 20 December 2017).

10. Croft MA, Kaufman PL, Erickson-Lamy K, Polansky JR, Accommodation and ciliary muscle muscarinic receptors after echothiophate, IOVS, 1991;32:3288-97.

11. Pavan-Langston $D$, Manual of Ocular Diagnosis and Therapy, Wolters Kluwer Health/Lippincott Williams \& Wilkins, 2008

12. Kaufman $S$, Addressing presbyopia pharmacologically, Ophthalmology Times, 2012. Available at: http:// Ophthalmology Times, 2012. Available at: htp://
ophthalmologytimes.modernmedicine.com/ ophthalmologytimes.modernmedicine.com/
ophthalmologytimes/content/addressing-presbyopiaophthalmologytimes/content/addressing-presby)
pharmacologically (accessed 14 October 2017)

13. Abdelkader $\mathrm{A}$, Improved presbyopic vision with miotics, Eye Contact Lens, 2015;41:323-7.

14. Abdelkader A, Kaufman $\mathrm{HE}$, Clinical outcomes of combined versus separate carbachol and brimonidine drops in correcting presbyopia, Eye Vis, 2016;3:31

15. Vejarano $L F$, Ophthalmic formulation and method for ameliorating presbyopia, 2012. Patent publication number: US20140024642 A1. Available at: http://bit.ly/Vejarano (accessed 14 October 2017)

16. Feinbaum CG, Patel S, Šalamun F, Pharmacological ophthalmic composition for use in the correction of presbyopia and its administration, 2014. Patent publication number: W02015122853 A1. Available at: http://bit.ly/feinbaum (accessed 14 October 2017)

17. Renna A, Vejarano LF, De la Cruz E, Alió JL, Pharmacological Treatment of Presbyopia by Novel Binocularly Instilled Eye Drops: A Pilot Study, Ophthalmol Ther, 2016:5:63-73.

18. Krader $\mathrm{CG}$, Feinbaum C, Simple solution for presbyopia: topical agent acts by reducing pupil size to increase depth of focus. Ophthalmology Times, 2015. Available at: http://ophthalmologytimes.modernmedicine. com/ophthalmologytimes/news/simple-solution-

19. Kim T, A unique drop, Eyeworld, 2014. Available at: https://www eyeworld.org/article-a-unique-drop (accessed 14 October 2017).

20. Abad JC, Compositions and methods for treating presbyopia, mild hyperopia, and irregular astigmatism, 2012, Patent publication number: WO2013041967

21. Rodríguez HJV, Carrera DH , Composición oftálmica para la corrección de la presbicia ,2014,. Patent publication number: W02015092087A1. Available at: http://bit.ly/Rodríguez (accessed 14 October 14).

22. Renna A, Alió JL, Vejarano LF, Pharmacological treatments of presbyopia: a review of modern perspectives, Eye Vis (Lond). 2017;4:3.

23. Dell SJ, Eye drop may provide a pharmacological treatment for presbyopia, 2014. Available at: http://bit.ly/sjdello1 (accessed 14 presbyopia, 20
October 2017).

24. German EJ, Wood D, Hurst MA, Ocular effects of antimuscarinic compounds: is clinical effect determined by binding affinity for muscarinic receptors or melanin pigment? J Ocul Pharmacol Ther, 1999;15:257-69.

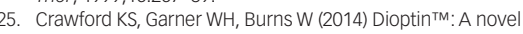
pharmaceutical formulation for restoration of accommodation in presbyopes, Invest Ophthalmol Vis Sci, 2014;55:3765.

26. Takemoto $\mathrm{L}$, Increase in the intramolecular disulfide bonding of alpha-a crystallin during aging of the human lens, Exp Eye Res, 1996;63:585-90.
27. EncoreHealth LLC, Choline esters, 2014, Patent publication number: US9326970 B2. Available at: http://bit.ly/cholineesters (accessed 14 October 2017).

28. Burns B, Encore Vision Reports Positive Phase I/II Results, 2016. Available at: http://bit.ly/EVO6presbyopia (accessed 14 October 2017)

29. Novartis AG, Novartis bolsters ophthalmology pipeline though the acquisition of Encore Vision, Inc, 2016. Available at: http:// bit.ly/encorenovartis (accessed 14 October 2017).

30. Presbyopia Therapies, "Evaluation of the efficacy and safety of PRX-100 in the treatment of early to moderate presbyopia", NCT02554396, ClinicalTrials.gov (2016). Available at: http://bit.ly/ NCT02554396 (accessed 14 October 2017).

31. Vejarano LF, Renna A, Dela Cruz E, Alió IL, Symptomatic Control of Presbyopia through Pharmacological Ciliary Body Stimulation, EC Ophthalmology, 2017;5:106-20.

32. Moustafa FA, Sandoval LF, Feldman SR, Rosacea: new and emerging treatment, Drugs, 2014;74:1457-65.

33. Allergan, Safety and efficacy of AGN-199201 and AGN-190584 in patients with presbyopia, Identifier: NCT02197806, ClinicalTrials. gov, 2014. Available at: http://bit.ly/NCT02197806 (accessed 14 October 2017)

34. Allergan, A study of the concurrent use of AGN-190584 and AGN-199201 in participants with presbyopia, ClinicalTrials. gov Identifier: NCT02595528, 2016. Available at: http://bit.ly/ NCT02595528 (accessed 14 October 2017).

35. Sharma A, Optical correction, 2009. Patent publication number: US20090156606 A1. Available at: http://bit.ly/sharmacorrection (accessed 14 October 2017)

36. Pilocarpine hydrochloride (solution, ophthalmic) monograph 2009. Available at: http://bit.ly/pilocarpinemono (accessed 14 October 2017)

37. Small S, Stewart-Jones JH, Influence of thymoxamine on changes in pupil diameter and accommodation produced by homatropine and ephedrine, Br J Ophthalmol, 1976;60:132-4.

38. Wilcox CS, Heiser JF, Crowder AM, Wassom NJ et al., Comparison of the effects on pupil size and accommodation of three regimens of topical dapiprazole, Br J Ophthalmol, 1995; $79: 544-8$

39. Balal S, Gil-Cazorla R, Naroo SA, Sharma A, Shah S, Eyedrops for presbyopia. Myth or medicine?, The Ophthalmologist, 2017;37:16-27. 